\title{
Remediation of As/Cr co-contaminated soil by electrokinetic coupled with permeable reactive barrier
}

\author{
Yunfeng Xu, Yangfan Fang, Kaili Wang, Wei Xia, Guangren Qian ${ }^{\dagger}$ \\ School of Environmental and Chemical Engineering, Shanghai University, No.99 Shangda Road, Shanghai 200444, China
}

\begin{abstract}
In this study, the permeable-reactive-barrier (PRB) assisted electrokinetic (EK) was used to remediate As/Cr Co-contaminated soil, aiming to explore the optimal remediation conditions and the migration of As/Cr. The effects of PRB active substance, PRB location, voltage gradient and running time on the migration and transformation of $\mathrm{Cr}$ and $\mathrm{As}$ in simulated $\mathrm{As} / \mathrm{Cr}$ contaminated kaolin were studied. The optimal parameters were as follows: PRB position was located near the anode (PRB A, the medium of PRB was hydrocalumite (CaAl-LDH)), initial voltage gradient was $1 \mathrm{~V} / \mathrm{cm}$, running time was $96 \mathrm{~h}$. Under the optimal conditions, the removal efficiency of total arsenic (TAs) and total chromium (TCr) were $40.1 \%$ and $81.0 \%$, respectively. This indicated that EK can effectively migrate As and Cr, and PRB can effectively adsorb As and $\mathrm{Cr}$. The migration of As tends to both anode and cathode, while $\mathrm{Cr}$ tends to migrate towards the anode. The XRD patterns and FTIR spectra confirmed that the As immobilized by CaAl-LDH was mainly adsorbed on the surface, while Cr existed in CaAl-LDH by surface adsorption and intercalation.
\end{abstract}

Keywords: As/Cr co-contaminated soil, CaAl-LDH, CaFe-LDH, EK-PRB

\section{Introduction}

Due to the high toxicity, persistence and carcinogenicity of heavy metals, global concerns of contaminated soil by heavy metals are growing [1]. Among them, cadmium $(\mathrm{Cd})$, arsenic $(\mathrm{As})$, lead $(\mathrm{Pb})$ and chromium $(\mathrm{Cr})$ are the most familiar pollutants in heavy metal contaminated soil [2]. Various studies have shown that human activities are one of the main reasons for the formation of heavy metals in the environment [3, 4]. Extensive industrial and agricultural events such as the manufacture of pyrotechnics and electronic products, as well as the usage of Cr-containing phosphate fertilizers, can cause the severe excessiveness of $\mathrm{Cr}[5,6]$. Accumulation of As in soils is due to the usage of As-containing pesticides, the combustion of fossil fuels, the dumping of tailings and industrial wastes [5-8]. Unlike other contaminants, microorganisms or chemicals cannot degrade them once the heavy metals enter the soil environment $[9,10]$. Heavy metals mainly affects the liver, kidneys and lungs of human and may also cause dermatitis and skin ulcers [11]. With the increasing public demand for environmental health, the remediation of heavy metal contaminated soil has been put on the agenda, and more and more attention has been paid by

This is an Open Access article distributed under the terms of the Creative Commons Attribution Non-Commercial License (http://creativecommons.org/licenses/by-nc/3.0/) which permits unrestricted non-commercial use, distribution, and reproduction in any medium, provided the original work is properly cited.

Copyright (C) 2022 Korean Society of Environmental Engineers the academic community.

Researchers have researched and developed a variety of techniques for the remediation of heavy metals in contaminated soil, especially flushing [12], phytoremediation [12, 13], excavation and stabilization [5]. Traditional ex-situ restoration methods such as soil replacement and flushing are often cost prohibitive, and require significant capital investment in labor and material resources. Various reports have indicated that electrokinetic (EK) remediation is one of the most potential in-situ technologies for the treatment of heavy metals contaminated soil, such as $\mathrm{Cu}, \mathrm{Zn}, \mathrm{Pb}, \mathrm{Cd}, \mathrm{Cr}, \mathrm{Ni}, \mathrm{Hg}$, As [14-16]. Zhou et al. [17] used electrodynamic method to remediate $\mathrm{Cu} / \mathrm{Zn}$ co-contaminate soil, and the removal efficiency of $\mathrm{Cu}$ and $\mathrm{Zn}$ reached $63 \%$ and $65 \%$ respectively. However, EK can only make the pollutants in the soil move to the designated region, but cannot eliminate the pollutants. Therefore, EK is often combined with other technologies to achieve the effect of migrating and removing pollutants in the soil. For example, Afshinnasiri et al. [17] used EK in combination with PRB and EDTA to remove $70 \%$ of $\mathrm{Cr}$ in the soil. Ali Baratifardin et al. [18] combined the use of EK with anionic and non-ionic surfactants, which can improve the kerosene re-

Received January 07, 2021 Accepted March 20, 2021

${ }^{\dagger}$ Corresponding author

E-mail: grqian@shu.edu.cn

Tel: +862166137758 Fax: +862166137758

ORCID: 0000-0001-6021-5212 
moval efficiency by $37 \%$ compared with the traditional use of EK. Sajadadhami et al. [19] used electrokinetic method combined with Fenton technology to remove 93\% of phenanthrene in the soil, and the removal efficiency was $100 \%$ higher than that of traditional electrokinetic method. Among the above combined technologies, the technology combining EK and PRB can improve the removal efficiency of pollutants and the performance of EK by accelerating the transport of pollutants, thus reducing manpower and material inputs [20-23].

A variety of materials have been developed for use as PRB reaction media, such as $\mathrm{Fe}_{3} \mathrm{O}_{4}$ [22], zero-valent iron (ZVI) [24, 25], red mud [26], microorganism [27], humin [28] and activated carbon [29]. However, ZVI is easily affected by $\mathrm{pH}$, ion composition and other factors, which will lead to PRB precipitation in the degradation process, thus reducing its permeability, reactivity and durability [19, 28]. Layered double hydroxides (LDHs) is an increasing concern due to their low cost and long-term operability as PRB materials [21, 30]. Meanwhile, recent studies have found that $\mathrm{LDHs}$ also has the ability to remove oxyanion contaminants. Among them, calcium-based LDH has received widespread attention due to its low cost and easy availability. Li et al. [31] found that CaAl-LDH has an excellent adsorption capacity of $\mathrm{Cr}$ (VI) and U (VI), and the maximum adsorption was up to $104.82 \pm 0.02 \mathrm{mg} / \mathrm{g}$ and $54.79 \pm 0.02$ $\mathrm{mg} / \mathrm{g}$, respectively. Lu et al. [32] used CaFe-Cl-LDH and $\mathrm{CaFe}-\mathrm{NO}_{3}-\mathrm{LDH}$ to adsorb arsenate. The maximum adsorption capacity was $150.5 \mathrm{mg} / \mathrm{g}$ and $148.0 \mathrm{mg} / \mathrm{g}$, respectively. Common calcium-based LDHs are CaFe-LDH and CaAl-LDH. However, no studies have compared the application of CaFe-LDH and $\mathrm{CaAl}-\mathrm{LDH}$ to the remediation of heavy metal contaminated soils. Therefore, this article aims to use low-cost and easy-to-obtain $\mathrm{CaAl}-\mathrm{LDH}$ and $\mathrm{CaFe}-\mathrm{LDH}$ combined with EK to remediate heavy metal contaminated soil.

Numerous studies have evaluated the potential of EK-PRB techniques to treat heavy metals contamination in soil. However, most of the surveys were carried out on soils contaminated with single metals. The previous work of our group [14, 21] only explored the remediation of single metal (Cr) contaminated soil by EK-PRB technology in detail. Cappai et al. [26] enhanced the removal of $\mathrm{Cr}$ and As by transforming red mud (TRM) into an active material for PRB, and evaluated the synergic interaction between the EK and the PRB system. Yuan et al. [33] used cobalt-supported carbon nanotubes (CNT-Co) as PRB active materials to study EDTA-enhanced EK-PRB remediated As (V) contaminated soil, and the removal efficiency was $63 \%$ after $5 \mathrm{~d}$ of remediation . The removal efficiency of As was only 35\%. Currently, using $\mathrm{LDHs}$ to remediate polymetallic contaminated soil is relatively rare. From the foregoing, oxygen anions can be adsorbed by $\mathrm{LDH}$. The common heavy metals in the soil in the form of oxygen anions are As and Cr. Therefore, this article explores the remediation of $\mathrm{As} / \mathrm{Cr}$ co-contaminated soil by $\mathrm{CaAl}-\mathrm{LDH}$ and $\mathrm{CaFe}-\mathrm{LDH}$.

In summary, the purpose of this study is to investigate (i) the effect of PRB material, PRB position, initial voltage gradient and run time on the removal efficiency of As and $\mathrm{Cr}$ in the EK-PRB synergistic system, (ii) the migration direction and behavior of As and $\mathrm{Cr}$ in EK-PRB systems.

\section{Materials and Methods}

\subsection{Materials}

The commercial kaolin soil was used in this research. The contaminated soil with As (III) (100 mg/kg) and Cr (VI) (500 mg/kg) was prepared by sodium arsenite and potassium dichromate. In detail, commercial kaolin was placed into beaker with distilled water (the ratio of soil to water is 2:1), then a mixture of sodium arsenite and potassium dichromate was added. The soil sample was placed in a dry and ventilated place for $30 \mathrm{~d}$. The PRB media were $\mathrm{CaAl}-\mathrm{LDH}$ and $\mathrm{CaFe}-\mathrm{LDH}$, which were prepared by co-precipitation method [34]. The prepared LDH material was repeatedly washed 2 - 3 times with nitrogen-filled distilled water, dried at $105^{\circ} \mathrm{C}$, then passed through a 100 -mesh sieve and stored for use.

\subsection{Experimental Setup and Procedures}

The EK-PRB experiment was performed in a laboratory scale plexiglass apparatus consisting of plexiglass, electrodes, direct current (DC) power Supply, soil and PRB. The schematic diagram of the EK-PRB device $(250 \mathrm{~mm} \times 100 \mathrm{~mm} \times 100 \mathrm{~mm}$ in length $\times$ width $\times$ height) used in this experiment is illustrated in Fig. 1. A total of 7 sampling regions (S0-S6) were divided from anode to cathode. Two flaky graphite electrodes were vertically inserted into the uncontaminated soil, and when energized, they serve as the anode and the cathode, respectively. In every operation, Cr-As co-contaminated soil was filled (about $4 \mathrm{~cm}$ ). However, the As and Cr-free soil was placed into S0 region, anode and cathode. $\mathrm{A}, \mathrm{B}$ and $\mathrm{C}$ were the filling sites for active material of the permeable reactive wall in the experiment. $8.1 \mathrm{~g}$ of active material was filled corresponding to the contaminated soil concentration, and the LDH was fixed in the soil using nylon cloth and acrylic porous plate. The thickness of PRB was maintained at $6 \mathrm{~mm}$.Adjust the voltage of the DC power supply to control the soil to constant voltage. The way that the DC power supply was regulated and the voltage applied to the soil were consistent with our previous work [14].

In this experiment, the plate-shaped graphite electrodes were directly inserted into the wet soil. Soil moisture contents of all tests were $30 \%$ according previous report [21]. The removal efficiency of TCr and TAs by different PRB insertion sites (A, A + $\mathrm{B}, \mathrm{A}+\mathrm{C})$, voltage gradients $(1,1.5$ and $2 \mathrm{~V} / \mathrm{cm})$, running time (24, 48, 72, 96 and $120 \mathrm{~h}$ ) and different PRB materials (CaAl-LDH and $\mathrm{CaFe}-\mathrm{LDH}$ ) were investigated. All experiments are shown in Table 1.

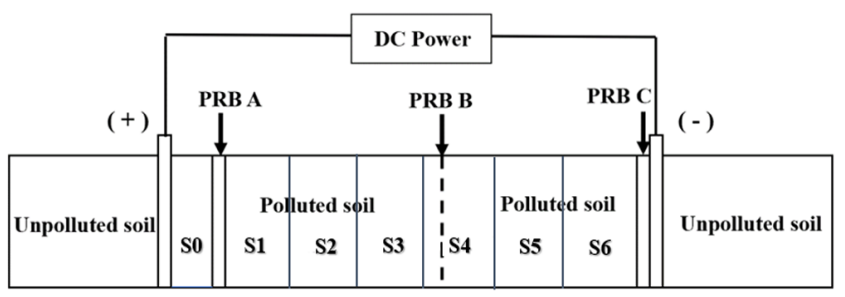

Fig. 1. The diagram of laboratory electric device and sampling point distribution. 
Table 1. Different Experimental Conditions

\begin{tabular}{|c|c|c|c|c|}
\hline Experiment & PRB materials & PRB insertion sites & voltage gradients $(\mathrm{V} / \mathrm{cm})$ & running time (h) \\
\hline Effects of PRB materials & $\begin{array}{l}\text { CaAl-LDH } \\
\text { CaFe-LDH }\end{array}$ & A & 1 & $24,48,72$ \\
\hline Effect of the PRB position & CaAl-LDH & $\mathrm{A}, \mathrm{A}+\mathrm{B}, \mathrm{A}+\mathrm{C}$ & 1 & $24,48,72,96$ \\
\hline Effects of initial voltage gradient & CaAl-LDH & A & $1,1.5,2$ & 72 \\
\hline Effects of running time & CaAl-LDH & A & 1 & $24,48,72,96,120$ \\
\hline XRD and FTIR & CaAl-LDH & A & 1 & $0,24,48,72,96,120$ \\
\hline
\end{tabular}

\subsection{Analytical Methods}

During the entire experiment, the soil conductivity was measured by a multimeter (Model VC890C+, Shenzhen Victor Hi-Tech, China). The calculation of current density refers to the previous work [14]. The soil $\mathrm{pH}$ was determined by a $\mathrm{pH}$ meter (Model LI-120) and a glass electrode (Model CL 51), with the soil to water ratio of 2:1.To determine TAs and TCr, $0.15 \mathrm{~g}$ of dry soil was digested in $10 \mathrm{~mL}$ of $\mathrm{HNO}_{3}$ and $2 \mathrm{~mL}$ of $\mathrm{HClO}_{4}$, then digested in $5 \mathrm{~mL}$ of $\mathrm{HF}$ and $2 \mathrm{~mL}$ of $\mathrm{HClO}_{4}$ until the solution was clear and transparent. The specific concentrations of obtained TCr/TAs were measured by inductively coupled plasma-atomic emission spectroscopy (ICP-AES) (Model Prodidy, Leeman). The XRD patterns were obtained using a Dmax/RB diffractometer (Rigaku Co.) in which $\mathrm{Cu} \mathrm{K} \alpha$ radiation $(\lambda=0.15406 \mathrm{~nm})$ was carried out at $40 \mathrm{kV}$ and $100 \mathrm{~mA}$. Approximately $1.5 \mathrm{mg}$ of the sample was uniformly mixed with $300 \mathrm{mg}$ of $\mathrm{KBr}$ (Uvasol) and compressed under vacuum to make $1.3 \mathrm{~cm}$ particles[35], and then FTIR spectra were obtained by FTIR 380 (Thermo Fisher Scientific).

\section{Results and Discussions}

\subsection{Effects of PRB Materials on EK-PRB Systems}

To investigate the effect of PRB materials on the concentration of TAs and TCr, TAs and TCr concentration in soil with different PRB materials after 24, 48 and $72 \mathrm{~h}$ are shown in Fig. 2.

The concentration of residual TAs is shown in Fig. 2(a). In CaAl-LDH system, S1 region, the accumulation of TAs was $98.8 \%$ in $24 \mathrm{~h}$; In S1 - S6 regions, the concentration of residual TAs decreased with the increase of time, indicating that As migrated to the location of PRB and was adsorbed by PRB. In contrast, in the CaFe-LDH system, the accumulation efficiency of TAs in the $\mathrm{S} 1$ region within $24 \mathrm{~h}$ was $88.9 \%$. In the S1 - S6 regions, except for the S1 region (48 h), the residual amount of TAs decreased with the increasing of time, which was caused by the dissolution of $\mathrm{CaFe}-\mathrm{LDH}$ in S1 region (48 h). In Fig. 2(c) and 2(d), the increase of calcium content and $\mathrm{pH}$ value in $\mathrm{S} 1$ region (48 h) also confirmed the dissolution of LDH. Except for S1 region (48 h), the concentration of residual TAs in CaAl-LDH system was higher than that in $\mathrm{CaFe}-\mathrm{LDH}$ system in $24 \mathrm{~h}$ and $48 \mathrm{~h}$.

For $72 \mathrm{~h}$, except for S6 region, the TAs concentration in other regions of CaAl-LDH system was lower than that of $\mathrm{CaFe}-\mathrm{LDH}$ system. It was because As in the S6 region of the CaAl- $\mathrm{LDH}$ system could not migrate to the PRB location in time and was captured by the PRB. Within $72 \mathrm{~h}$, the removal efficiency of TAs in CaAl-LDH and $\mathrm{CaFe}-\mathrm{LDH}$ systems were $35.6 \%$ and $34.2 \%$, respectively. During $48 \mathrm{~h}$ to $72 \mathrm{~h}$, the removal and migration of As in CaFe-LDH system were significantly lower than that in CaAl-LDH system. The reason was that $\mathrm{CaFe}-\mathrm{LDH}$ dissolved obviously [35], leading to the release of As, which could not be captured by PRB in time. In Fig. 2(c) and 2(d), the increase of calcium content and $\mathrm{pH}$ value of $\mathrm{CaFe}-\mathrm{LDH}$ at $72 \mathrm{~h}$ also confirmed the dissolution of $\mathrm{LDH}$ [35].

The concentration of residual TCr is shown in Fig. 2(b). In the S1 region of the CaAl-LDH system, the accumulation efficiency of TCr within $24 \mathrm{~h}$ was $168.3 \%$. This indicated that $\mathrm{Cr}$ near the cathode moved toward the anode and accumulated in the S1 region. Then the concentration of residual TCr decreased with the increasing of time in S1 - S6 regions; after $72 \mathrm{~h}$, the remaining $\mathrm{TCr}$ in the S3 - S6 regions accounted for 12\%. By comparison, in CaFe-LDH system, the accumulation of $\mathrm{TCr}$ was $84.3 \%$ in $24 \mathrm{~h}$; then the concentration of residual TCr decreased with the increasing of time; however, about 30\% Cr was remnant in S3 - S6 regions. The removal efficiency of TCr was $71.2 \%$ and $65.0 \%$ in $72 \mathrm{~h}$, respectively. It could be found that parts of $\mathrm{Cr}$ accumulated in soil and did not move to the anode in time.

Two experimental groups were designed to explore the effects of different Ca-based LDHs during the remediation process by EK-PRB. The relationship of Ca concentrations and remediation time of all regions are shown in Fig. 2(c).

The Ca concentration in each region indicated the dissolution of $\mathrm{LDH}$ and the migration direction of $\mathrm{Ca}$. In both Ca based $\mathrm{LDH}$ systems, Ca concentration reached the highest near the anode, and gradually decreased from S1 to S6 regions. In CaAl-LDH experiments, there was a slight increase of Ca concentrations with the increasing of time extension in each region. Compared with CaAl-LDH, the Ca concentration in CaFe-LDH experiment was significantly increased and finally migrated to the cathode. Based on above findings, it could be concluded that the migration of $\mathrm{Ca}$ to the cathode would happen. Moreover, it was easier for $\mathrm{Ca}$ to dissolve out in $\mathrm{CaFe}-\mathrm{LDH}$ experiments than in CaAl-LDH.

The changes of $\mathrm{pH}$ of every region after running for different time with different PRB is shown in Fig. 2(d). The soil pH of $\mathrm{CaFe}-\mathrm{LDH}$ system was much higher than that of CaAl-LDH system. The $\mathrm{pH}$ of S1 region was $6.43(24 \mathrm{~h}), 6.82$ (48 h) and 6.22 (72 h). The reason was that there was a large amount of $\mathrm{CaFe}-\mathrm{LDH}$ dissolution in the $\mathrm{CaFe}-\mathrm{LDH}$ system [36], which caused the increase of soil $\mathrm{pH}$. In the two systems, the soil $\mathrm{pH}$ value in S0 region decreased with the increasing of time, while the soil $\mathrm{pH}$ value in S6 region increased. 

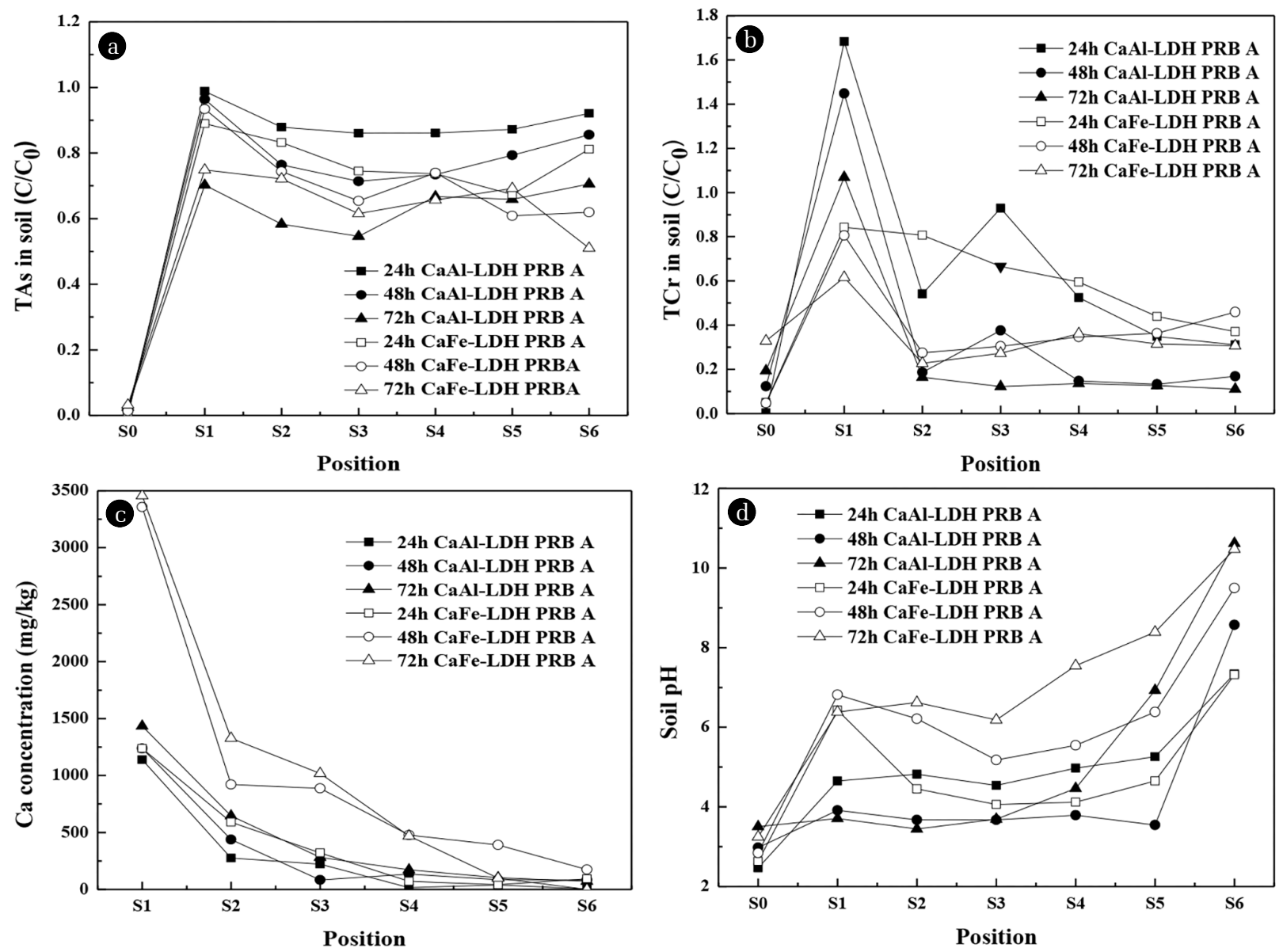

Fig. 2. (a) TAs concentration, (b) TCr concentration, (c) Ca concentration, and (d) $\mathrm{pH}$ in soil with different PRB after 24,48 and $72 \mathrm{~h}$.

\subsection{Effect of the PRB Position on EK-PRB Systems}

Fig. 3 and Fig. 4 show the concentration distribution of the two heavy metals and the change of soil $\mathrm{pH}$ respectively when PRB was placed in different locations.

In PRB A system (Fig. 3(a)), with the extension of operation time, the concentration of residual TAs in soil (S1 - S6 regions) decreased gradually, and the middle (S2 - S4 regions) decreased rapidly. Compared with PRB A system, the concentration of residual TAs in PRB A + B system gradually decreased (Fig. 3(b)), while the concentration of residual TAs in S4 - S6 regions was less than $40 \%$ - 65\% within $96 \mathrm{~h}$, because $\mathrm{LDH}$ placed in B position (middle) could capture heavy metal in time. In the PRB A + C system (Fig. 3(c)), the concentration of residual TAs fluctuated in most sample regions, because PRB C system could fix a part of As. The residual TAs in S5 - S6 regions were less than 20\% - 45\% within $96 \mathrm{~h}$. After $24,48,72$ and $96 \mathrm{~h}$ treatment, the removal efficiency of TAs were 10.3\%, 19.6\%, 35.6\% and 40.1\% in PRB A system, 16.3\%, 27.8\%, $37.4 \%$ and $42.9 \%$ in PRB A + B system, and 8.1\%, 21.2\% ,36.8\% and $39.2 \%$ in PRB A + C system. It can be seen from Fig. 4 that the final $\mathrm{pH}$ of contaminated soil in the S1 - S4 regions was 3.5 - 6, and the $\mathrm{pH}$ of S5 - S6 regions near the cathode was above 7.

From the Eh-pH diagram of As, when $\mathrm{pH}$ is 3.5 - 6, As (III) mainly exists in the form of $\mathrm{H}_{3} \mathrm{AsO}_{3}$, part of As (III) in the soil will be transformed into As (V), and As (V) mainly exists in the form of $\mathrm{H}_{2} \mathrm{AsO}_{4}{ }^{-}$, when $\mathrm{pH}$ is above than 7, As (V) mainly exists in the form of $\mathrm{HAsO}_{4}{ }^{2-}$, while $\mathrm{PRB}$ mainly adsorbs As in the form of anions, which can explain the effect of different PRB placement positions on As removal in different soil regions. Within $0-48 \mathrm{~h}$, the removal efficiency of TAs in the PRB A $+\mathrm{B}$ test was relatively high, which indicated that the remediation of PRB in B position was timely. With the increasing of time, the removal efficiency of the three groups were basically the same, which indicated that the PRB location had little effect on the removal of TAs in soil. It meant that multiple PRBs did not show higher utilization with the same quality $\mathrm{LDH}$ material.

The distribution of TCr concentration in the soil with different PRB positions after 24, 48, 72 and $96 \mathrm{~h}$ are shown in Fig. 3(d), 3(e) and 3(f). In PRB A system (Fig. 3(d)), the concentration of residual TCr in S2 - S6 regions decreased rapidly with the increasing of time, the concentration of residual TCr was 92.8\% (24 h), 37.6\% (48 h) and 12\% (72 - $96 \mathrm{~h}$ ) in S3 region which was caused by the local accumulation of $\mathrm{Cr}$ in this region from S4 - S6 regions. Compared with PRB A system, the residual TCr concentration in the PRB A + B system decreaseed slowly with the increasing of running time (Fig. 3(e)); because the $\mathrm{LDH}$ placed in the $\mathrm{B}$ position (middle) can capture pollutants in time, the concentration of re- 

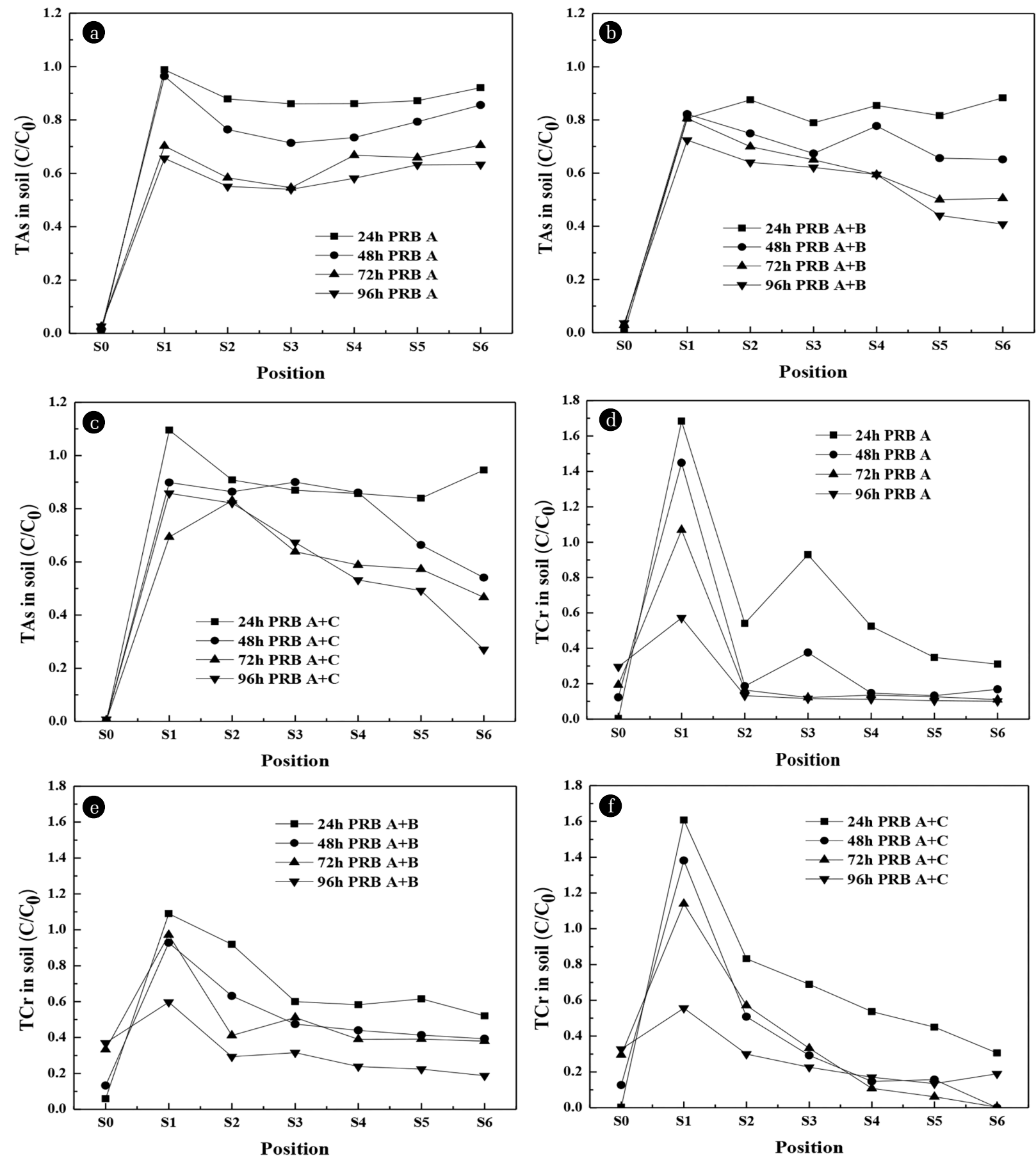

Fig. 3. TAs/TCr concentration in soil with different PRB locations after 24, 48, 72 and $96 \mathrm{~h}$ (TAs: (a) PRB A system; (b) PRB A + B system; (c) PRB A + C system; TCr: (d) PRB A system; (e) PRB A + B system; (f) PRB A + C).

sidual TCr was 109.0\% (24 h), 92.8\% (48 h), 97.1\% (72 h) and $55.6 \%$ (96 h) in S1 region. In PRB A + C system (Fig. 3(f)), the concentration of residual TCr decreased at the slowest rate and was much lower in S5 - S6 regions; Due to the setting of multiple PRBs to form a certain resistance, the migration of $\mathrm{Cr}$ was blocked; the concentration of residual TCr of S1 region was 160.8\% (24 h), 141.1\%
(48 h), 114.0\% (72 h) and 59.6\% (96 h). After 24, 48, 72 and 96 h treatment, the removal efficiency of TCr was $27.7 \%, 59.0 \%, 71.2 \%$ and $81.0 \%$ in PRB A system; 27.9\%, 45.3\%, 49.1\% and 69.1\% in PRB A+B system; 26.3\%, 58.6\%, 63.1\% and 73.7\% in PRB A + $\mathrm{C}$ system. The removal efficiency of TCr is similar in the first 24 $\mathrm{h}$, but with the increasing of running time (48 - $96 \mathrm{~h}$ ), the removal 
efficiency of PRB A system was the best. It was demonstrated that the PRB A could reduce the concentration of $\mathrm{TCr}$ in part of regions, while the PRB B hinder the migration of Cr.

The soil used in the experiment was kaolin soil mixed with hexavalent chromium (Cr (VI)) and trivalent arsenic (As(III)). According to the migration and removal of As and $\mathrm{Cr}$ in the compound
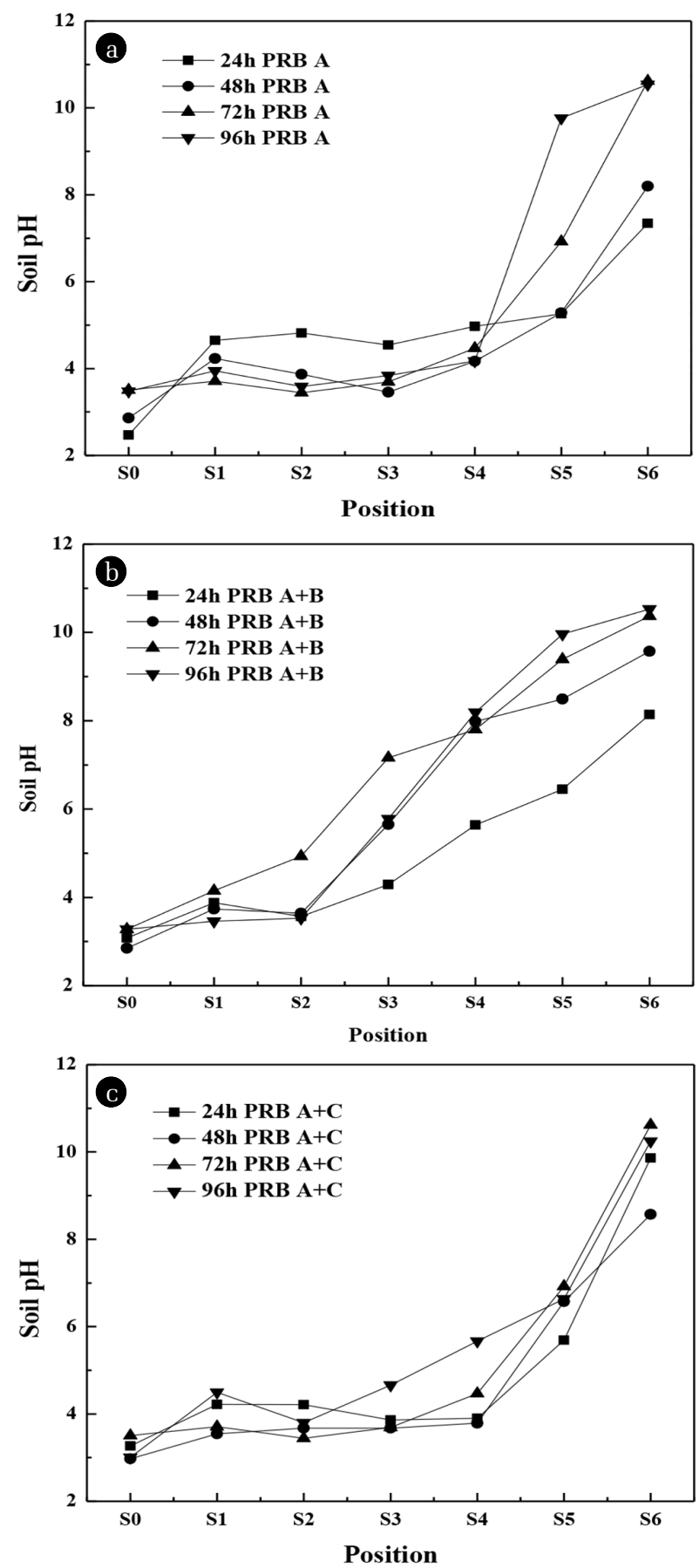

Fig. 4. $\mathrm{pH}$ in soil with different PRB locations after 24, 48, 72 and 96 h. (a) PRB A system, (b) PRB A + B system, (c) PRB A + C system. contaminated soil, it could be found that the migration of As tends to move to the two poles, and the migration of $\mathrm{Cr}$ tended to move to the anode. The migration of As and $\mathrm{Cr}$ in soil mainly occurred in soil solution under electrokinetic action. The final $\mathrm{pH}$ of contaminated soil in the test system was $3.5-6$, and the $\mathrm{pH}$ of S5 - S6 regions near the cathode was above 7.

From the Eh-pH diagram of As, in our system, As (III) mainly exists in the form of $\mathrm{H}_{3} \mathrm{AsO}_{3}$, part of As (III) in the soil will be transformed into As (V). As (V) mainly exists in the form of $\mathrm{H}_{2} \mathrm{AsO}_{4}{ }^{-}$ and $\mathrm{HAsO}_{4}{ }^{2}{ }^{-}$[37]. According to the Eh-pH diagram of $\mathrm{Cr}$, Cr (VI) mainly exists in the form of $\mathrm{Cr}_{2} \mathrm{O}_{7}{ }^{2}$ [38]. PRB was easy to capture $\mathrm{Cr}$ (VI), and part of Cr (VI) in soil was transformed into Cr (III). $\mathrm{Cr}$ (III) was formed by the interaction of soil organic matter and microorganisms [14]. Cr (III) in soil was easy to be adsorbed by soil particles or form hydroxide, which limited the movement of $\mathrm{Cr}$ to cathode. The anions in soil solution tend to migrate to the anode through electromigration, and the non-ionic substances tend to migrate to the cathode through electroosmosis [22]. Therefore, As migrated to the two poles, which affected the directional migration and the removal of TAs; while most $\mathrm{Cr}$ migrated toward anode, which was conducive to the removal of $\mathrm{Cr}$.

\subsection{Effects of initial Voltage gradient on EK-PRB Systems}

The variation of current density of the device during $72 \mathrm{~h}$ operation under different voltage gradients are shown in Fig. 5(a). In general, the current density increased as the voltage increased. When the soil constant voltage was $1,1.5,2 \mathrm{~V} / \mathrm{cm}$, the initial current density of the soil was $1.12,1.57$ and $2.11 \mathrm{mV} / \mathrm{cm}^{2}$, respectively. In the first $2 \mathrm{~h}$, when the constant voltage was $1 \mathrm{~V} / \mathrm{cm}$, the current density of the soil increased to $1.26 \mathrm{mV} / \mathrm{cm}^{2}$; when the constant voltage was 1.5 and $2 \mathrm{~V} / \mathrm{cm}$, the current density of the soil decreased to 1.32 and $1.97 \mathrm{mV} / \mathrm{cm}^{2}$, respectively. At $72 \mathrm{~h}$, when the constant voltage was $1 \mathrm{~V} / \mathrm{cm}$, the current density of the soil was reduced to $0.51 \mathrm{mV} / \mathrm{cm}^{2}$; when the constant voltage was 1.5 and $2 \mathrm{~V} / \mathrm{cm}$, the current density of the soil continued to decrease to 0.42 and $0.46 \mathrm{mV} / \mathrm{cm}^{2}$, respectively. The current density tended to decrease under the high voltage gradient. Under a low voltage gradient, the current density tended to rise and then fell. When the voltage gradient was small, it took some time for the ions in the soil to dissolve. During this time, as the dissolved electrons increased, the current density continued to rise. The lower the applied voltage gradient, the more obvious the current density would increase firstly and then decrease. This phenomenon was similar with other researchers [24, 39].

Under the conditions of different voltage gradients, the concentration of residual TAs/TCr at each soil region after $72 \mathrm{~h}$ are shown in Fig. 5(b) and 5(c), respectively. The concentration of residual TAs increases as the voltage gradient increased. Under the voltage gradients of $1 \mathrm{~V} / \mathrm{cm}$, the concentration of residual TAs in the S2 and S3 regions was lower (Fig. 5(b)), which were 58.3\% and 54.6\%, respectively; S4 - S6 regions distributed between 65\% - 70\%. Compared with $1.0 \mathrm{~V} / \mathrm{cm}, \mathrm{S} 2$ - S3 regions were much higher under 1.5 and $2 \mathrm{~V} / \mathrm{cm}$. Under $1.5 \mathrm{~V} / \mathrm{cm}$, the concentration of residual TAs in the S2 and S3 regions were $74.5 \%$ and $75.7 \%$, respectively; S4 - S6 regions distributed between 55\% - 70\%; Among them, in the S5 region, the concentration of residual TAs was the lowest, which was $55.6 \%$. Under $2 \mathrm{~V} / \mathrm{cm}$, As accumulated in S5 region, 

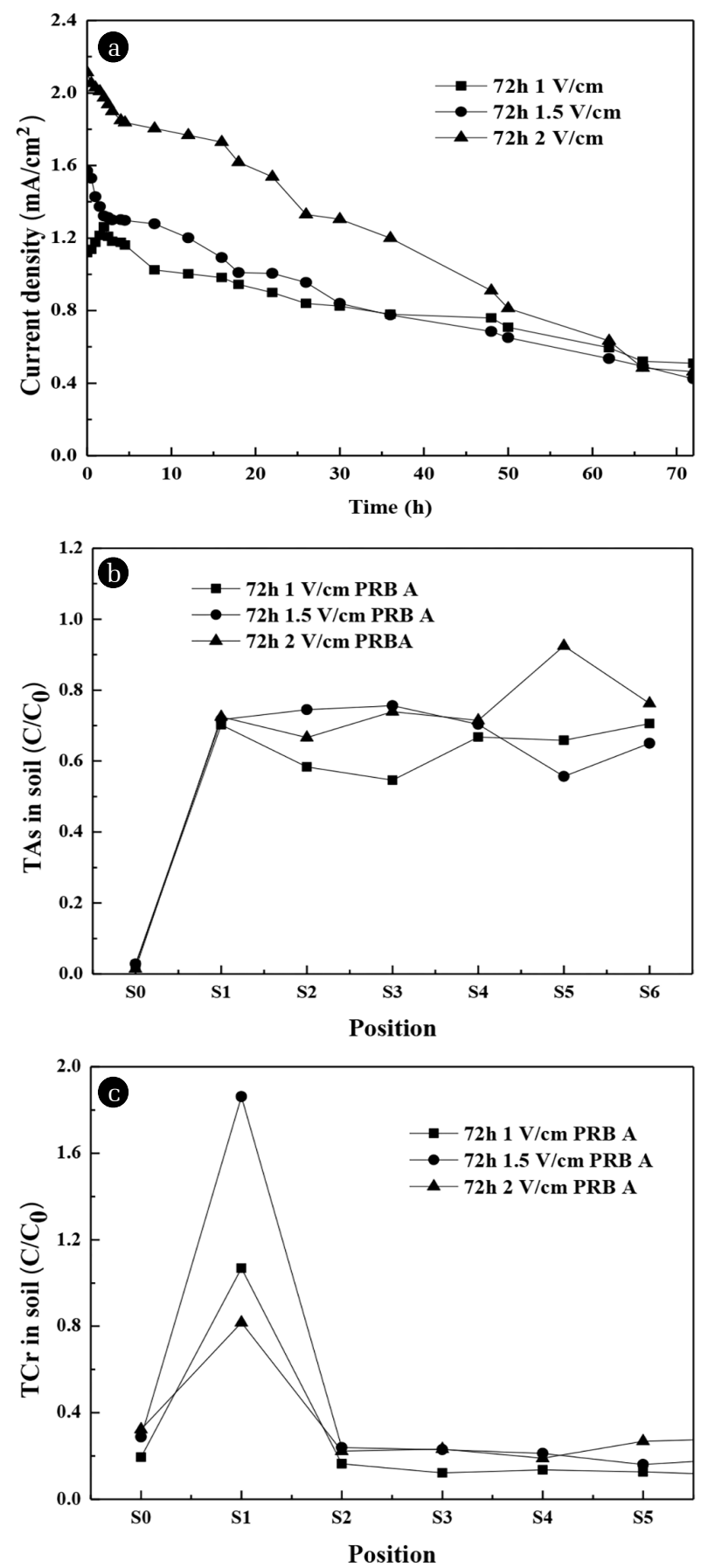

Fig. 5. Change of current density (a), TAs (b) and TCr (c) concentration with different voltage gradients.

which reached 92.5\%; the concentration of residual TAs in the S2 - S3 regions were $66.7 \%$ and $74.0 \%$, respectively; S4 - S6 regions distributed between $71 \%$ - 92.5\%. Through calculating, the average removal efficiency of TAs in the S1 - S6 regions were 35.6\%, 31.2\% and $24.5 \%$ under $1,1.5$ and $2 \mathrm{~V} / \mathrm{cm}$. The concentration of residual TAs was essentially zero in the So region under all conditions, indicating that PRB can effectively capture As.
As the voltage gradient increased, the concentration of residual TCr increased first and then decreased. It can be seen from Fig. 5(c) that the concentration of residual TCr in the S2 - S6 regions was less than $30 \%$ under the voltage gradients of $1,1.5$ and $2 \mathrm{~V} / \mathrm{cm}$, and the lowest at $1 \mathrm{~V} / \mathrm{cm}$. In the S1 region, the residual $\mathrm{TCr}$ was $106.9 \%, 186.2 \%$ and $81.7 \%$, respectively. Through calculating, removal efficiency of TCr in the S1 - S6 regions were $72.1 \%, 51.8 \%$ and $66.5 \%$ under 1, 1.5 and $2 \mathrm{~V} / \mathrm{cm}$. Meanwhile, under different voltage gradients, the TAs content in the S0 region was 19.4\%, 28.7\% and $32.3 \%$, respectively. The results showed that the Cr was more likely to penetrate PRB under higher voltage gradients, which was due to the dissolution of the CaAl-LDH material [30, 36].

\subsection{Effects of Running Time on EK-PRB Systems}

The $\mathrm{pH}$ changes of each soil region under different running time are shown in Fig. 6(a). At the beginning of the experiment, the $\mathrm{pH}$ of As/Cr-free soil and As/Cr-contaminated kaolin soil was 3.22 and 3.52, respectively. The $\mathrm{pH}$ of S0 region was 2.47 (24 h), then increased to $3.50(72 \mathrm{~h})$, and decreased to 3.14 at $120 \mathrm{~h}$, which was caused by partial dissolution of $\mathrm{LDH}$. The trend of $\mathrm{pH}$ was similar with the increase of time in S1, S2, S3 and S4 regions, the $\mathrm{pH}$ was $4.65,4.82,4.54$ and 4.97 at $24 \mathrm{~h}$, then remained between 3.5 - 5.3. The $\mathrm{pH}$ of S5 and S6 regions increased to 6.92 and 10.62 at $72 \mathrm{~h}$; S5 region kept on rising to 9.76 at $96 \mathrm{~h}$ and then decreased to 9.5 at $120 \mathrm{~h}$; S6 region decreased slightly to 10.32 at $120 \mathrm{~h}$. Which was caused by the dissolution of the CaAl-LDH [36]. Meanwhile, during the remediation process, $\mathrm{H}^{+}$and $\mathrm{OH}^{-}$ were produced due to the presence of electric field. The $\mathrm{pH}$ of the soil changed due to the electrolysis of the cathode and anode. The distribution and change of soil $\mathrm{pH}$ are affected by the migration of $\mathrm{H}^{+}, \mathrm{OH}^{-}$and the initial concentration of other ions [15].

Fig. 6 shows the changes of residual TAs/TCr concentration with the increasing of time in every region. In Fig. 6(b), the changes of TAs were similar for S1 - S6 regions, except S3, S4 and S5 region increased slightly. In S1, S2, and S6 regions, the concentration of residual TAs gradually decreased with the increase of running time, which was $47.8 \%, 50.2 \%$ and $46.9 \%$ at $120 \mathrm{~h}$, respectively. The concentration of residual TAs in the S3 - S4 regions decreased to $54.0 \%, 58.1 \%$ and $63.2 \%$ at $96 \mathrm{~h}$, and increased to $60.2 \%, 68.7 \%$ and $73.0 \%$ at $120 \mathrm{~h}$, respectively. The concentration of residual TAs in S0 region raised gradually with the increasing of time. The TAs residual amount of was relatively homogenous in every region, which further testified that the migration of As in soil did not migrate in a certain direction.

In the Fig. 6(c), the concentration of residual TCr in S0 region was $0.3 \%$ (24 h), 12.3\% (48 h), 19.4\% (72 h), 29.6\% (96 h) and 31.3\% (120 h); Due to most of $\mathrm{Cr}$ migrated to PRB region, it rose to $168.3 \%$ ( $24 \mathrm{~h}$ ) and then gradually decreased to $45.6 \%$ (120 h) in the S1 region; In S2 - S6 regions, the concentration of residual TCr decreased with the increasing of time and was $29.0 \%, 13.7 \%, 10.2 \%, 10.8 \%$ and $11.0 \%$ in $120 \mathrm{~h}$, respectively. The concentration of residual TCr in the S0 region gradually increased with the increasing of time and was caused by the dissolution of $\mathrm{LDH}$. From the change of TCr concentration in each region with the increasing of time, it intimated that $\mathrm{Cr}$ tends to migrate toward the anode, mainly incorporation of $\mathrm{Cr}(\mathrm{VI})$ in the form of an anion, which tends to migrate toward the anode. 

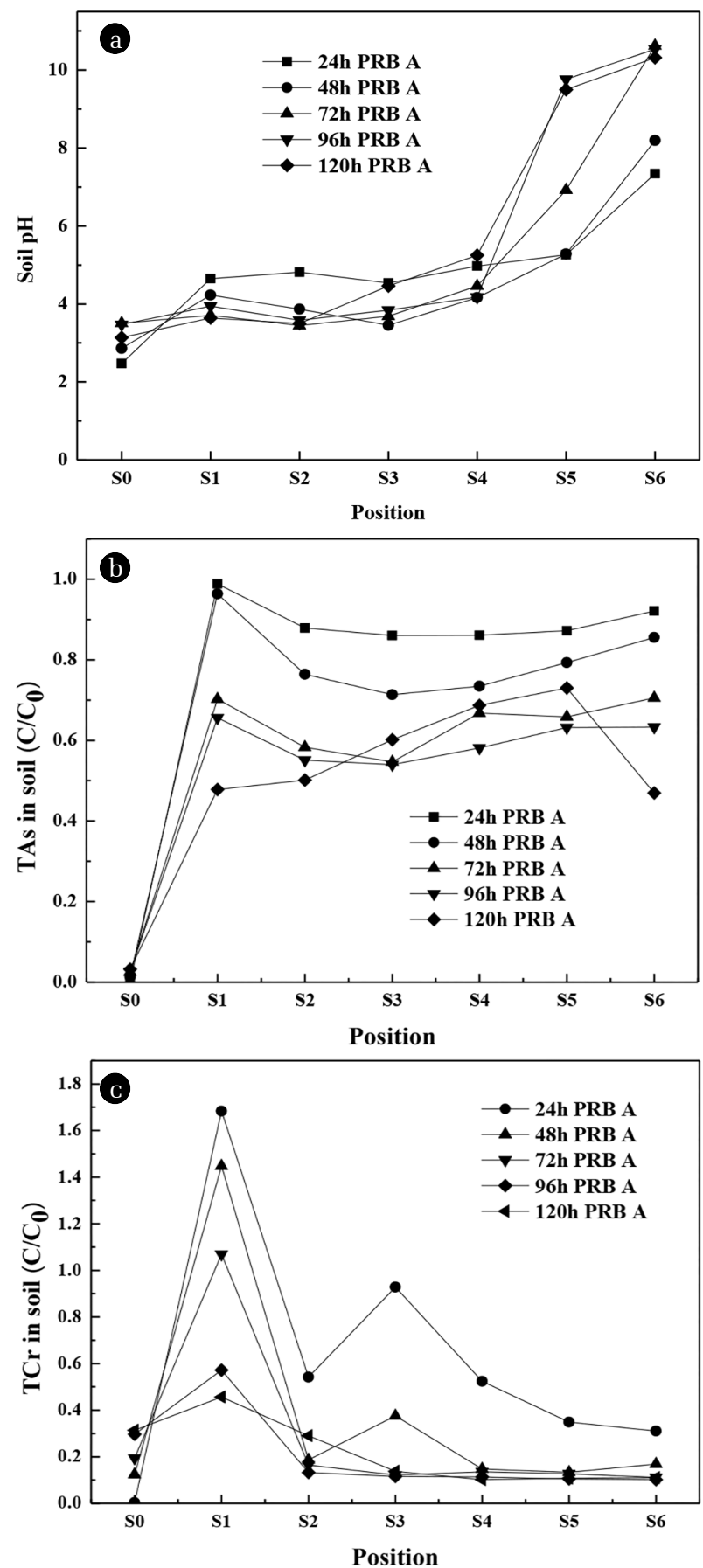

Fig. 6. $\mathrm{pH}(\mathrm{a})$, $\mathrm{TAs}(\mathrm{b})$ and $\mathrm{TCr}(\mathrm{c})$ concentration with different running time after 24, 48, 72,96 and $120 \mathrm{~h}$.

By calculation, the average removal efficiency of S1-S6 regions increased gradually during the period of $24-96 \mathrm{~h}$, the removal efficiency of TAs was $10.3 \%, 19.6 \%, 35.6 \%$ and $40.1 \%$, respectively and the removal efficiency of TCr was $27.7 \%, 59.0 \%, 71.2 \%$ and $81.0 \%$, respectively. After prolonging the running time to $120 \mathrm{~h}$, there was no significant increase in TAs and TCr removal efficiency, which were $42.2 \%$ and $80.0 \%$, respectively. More As and Cr accumu- lated in the So region with the increasing of time. This could be caused by the dissolution of the $\mathrm{CaAl}-\mathrm{LDH}$ and released again[40]. In previous study, it has demonstrated that $\mathrm{CrO}_{4}{ }^{2-}$ and $\mathrm{Cl}^{-}$during the dissolution-reprecipitation process in CaAl-LDH could exchange anion [30].

\subsection{The Function of CaAl-LDH as PRB Materials}

CaAl-LDH as PRB material could immobilize As and Cr. However, high moisture content and low $\mathrm{pH}$ near the anode could lead to the dissolution of CaAl-LDH, it had effects on the removal of As and $\mathrm{Cr}$. The recovery of CaAl-LDH and the concentrations of As and $\mathrm{Cr}$ were determined at $24 \mathrm{~h}, 48 \mathrm{~h}, 72 \mathrm{~h}, 96 \mathrm{~h}$ and $120 \mathrm{~h}$. The initial PRB content was $8.1 \mathrm{~g}$. As is shown in Table S1, the recovery of PRB decreased gradually with the increasing of time. The possibility was that the CaAl-LDH dissolved in EK-PRB system and there was some loss of LDH during the recovery process[30]. In the PRB system, the concentration of TAs was $1.96 \mathrm{mg} / \mathrm{kg}$ at $24 \mathrm{~h}$, then decreased to $13.17 \mathrm{mg} / \mathrm{kg}$ at $120 \mathrm{~h}$; while the concentration of TCr was $393.4 \mathrm{mg} / \mathrm{kg}$ at $24 \mathrm{~h}$, then increased to $1,285.3 \mathrm{mg} / \mathrm{kg}$ at $72 \mathrm{~h}$, was $982.6 \mathrm{mg} / \mathrm{kg}$ at $120 \mathrm{~h}$.

The XRD (a) pattern and FTIR (b) spectrum of CaAl-LDH before and after EK-PRB treatment are shown in Fig. 7 at different running time. According to Fig. 7(a), it was observed that the main characteristic peak (XRD) of CaAl-LDH was always maintained within 24 to $96 \mathrm{~h}$. After $72 \mathrm{~h}$ and $96 \mathrm{~h}$ of treatment, CaAl-LDH (JCPDS 43-0088) crystals still retain the original crystal form, while the weak characteristic peaks $(2 \theta=10.520$ and 21.131) of chromate hydrocalumite (CaAl-CrO4- $\mathrm{LDH}$, JCPDS 42-0063) were always displayed in the PRB medium. After $120 \mathrm{~h}$ of treatment, the characteristic intensity of $\mathrm{CaAl}-\mathrm{CrO}_{4}-\mathrm{LDH}$ was stronger, and more stray peaks appeared at the same time. The characteristic peaks ( of the new phase fitted well with those of chromate hydrocalumite $\left(\mathrm{Ca}_{4} \mathrm{Al}_{2}(\mathrm{OH})_{12} \mathrm{CrO}_{4}\left(\mathrm{H}_{2} \mathrm{O}\right)_{4}\right.$, JCPDS 42-0063) [14]. It was not observed significantly the insertion of As in $\mathrm{LDH}$.

Fig. 7(b) compares the FTIR of LDH after different running time. The original CaAl-LDH exhibited a typical FTIR pattern described in a previous report [14], in which the broad band centered at $3,485 \mathrm{~cm}^{-1}$ was attributed to the stretching vibrations of hydroxyl groups and $\mathrm{CaOH}$ [41]. The peak at $1,621 \mathrm{~cm}^{-1}$ came from the deformation vibrations of water molecules [42]. The peaks at 787 and $532 \mathrm{~cm}^{-1}$ were attributed to $\mathrm{v}(\mathrm{Al}-\mathrm{O})$ and $\mathrm{v}(\mathrm{Al}-\mathrm{OH})$ inside CaAl-LDH, respectively [43]. Moreover, an overlapped band at $1,460 \mathrm{~cm}^{-1}$ was attributed to the $\mathrm{v}\left(\mathrm{CO}_{3}{ }^{2-}\right)$. In addition, as the operating time of the device was extended, the vibration intensity at $3,485 \mathrm{~cm}^{-1}$ was gradually reduced due to the reaction of $\mathrm{O}-\mathrm{H}$ in CaAl-LDH with As and $\mathrm{Cr}$ in the device. The peaks around 787 and $532 \mathrm{~cm}^{-1}$ also began to decay (from 24 to $96 \mathrm{~h}$ ), whereas peak occurred at $877 \mathrm{~cm}^{-1}$ due to the vibration of Cr-O [44]. The width of the overlapped band at $1,460 \mathrm{~cm}^{-1}$ decreased with the increasing of running time, which could be explained by the $\mathrm{CO}_{3}{ }^{2-}$ gradual dissolution from the CaAl-LDH surface. Besides, the band at $1,040 \mathrm{~cm}^{-1}$ was a vibration of $\mathrm{Si}-\mathrm{O}$, it might be some kaolin during the recovery of PRB. Therefore, the CaAl-LDH could captured As and Cr. The removal mechanism of As by CaAl-LDH was surface adsorption, while the Cr was surface adsorption and intercalation. 

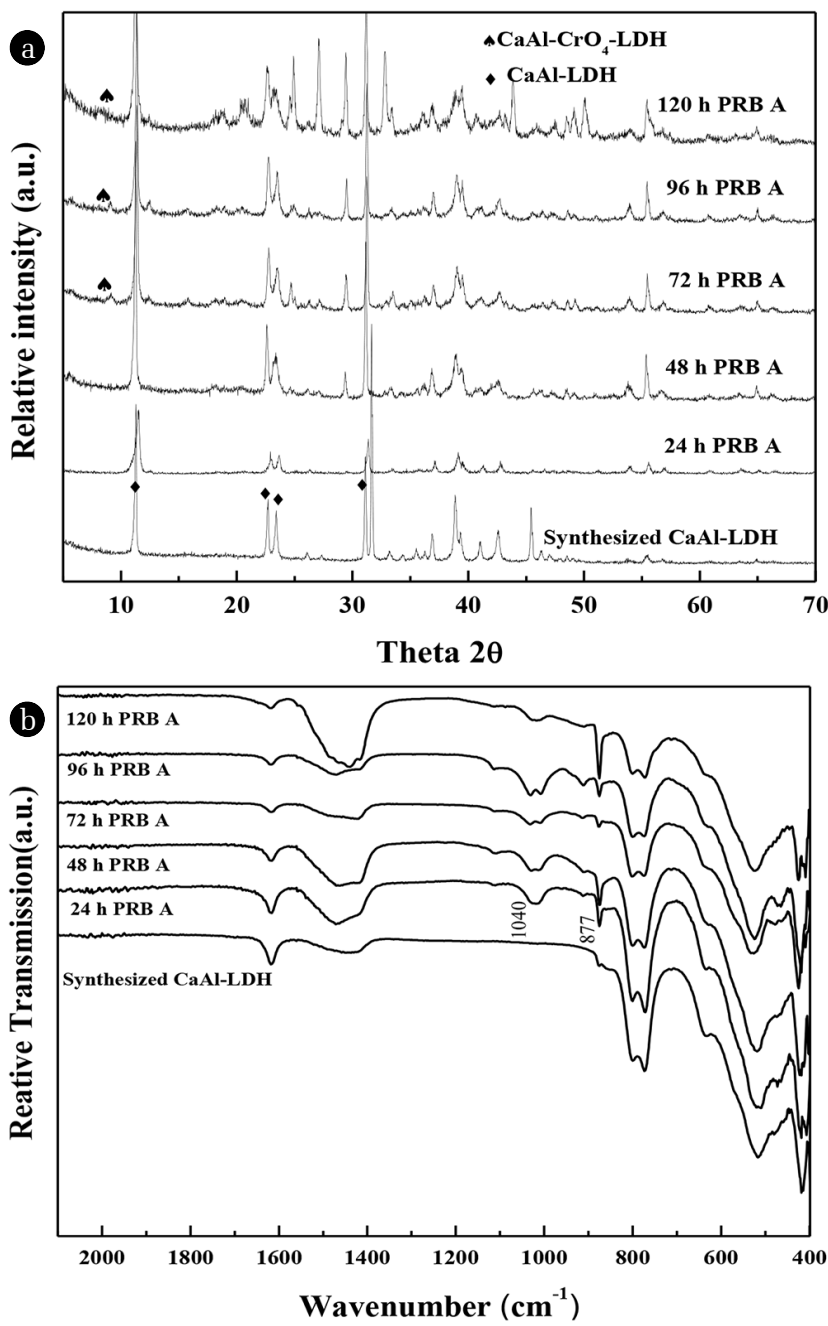

Fig. 7. The XRD pattern (a)and FTIR spectra (b) of LDH before and after EK-PRB treatment.

\section{Conclusions}

The effects of PRB active material, PRB position, voltage gradient and running time on the migration and conversion of $\mathrm{Cr}$ and As were studied in this paper. The poor stability of $\mathrm{CaFe}-\mathrm{LDH}$ resulted in a large amount of Ca dissolved and migrated to the cathode, so CaAl-LDH was selected as the PRB medium material. The location of PRB affected the migration and accumulation of As and $\mathrm{Cr}$ during the remediation process. When PRB was located near the anode (PRB A), the overall remediation effect was better than that of PRB A + B and PRB A + C. Under high voltage gradient, the pollutants were easier to pass through the PRB, so $1 \mathrm{~V} / \mathrm{cm}$ was the best voltage gradient. The results showed that the removal efficiency of TAs and TCr were $40.1 \%$ and $81.0 \%$, respectively at $96 \mathrm{~h}$. CaAl-LDH immobilized As mainly by surface adsorption, and $\mathrm{Cr}$ by surface adsorption and intercalation. In this study, EK-PRB could effectively remediate the As/Cr co-contaminated soil, because EK could make $\mathrm{As} / \mathrm{Cr}$ in the form of oxyanion migrate to the location of PRB, and PRB could effectively adsorb oxyanion. Therefore, the authors suggest that EK-PRB can also be applied to other oxyanion-contaminated soils. Additionally, other calcium-based substances will be considered as PRB materials in the future.

\section{Author Contributions}

Y.X. (Professor) completed part of the experiment and wrote the manuscript. Y.F.(M.S. student) completed part of the experiment and revised the manuscript. K.W. (M.S. student) wrote and revised the manuscript. W.X. (M.S. student) revised the manuscript. G.Q. (Professor) designed the experiment scheme and revised the manuscript.

\section{Acknowledgments}

This project is financially supported by the National Nature Science Foundation of China (No. 21878183).

\section{References}

1. Mao X, Han FX, Shao X, et al. Electro-kinetic remediation coupled with phytoremediation to remove lead, arsenic and cesium from contaminated paddy soil. Ecotoxicol. Environ. Saf. 2016;125:16-24

2. Jiang Y, Chao S, Liu J, et al. Source apportionment and health risk assessment of heavy metals in soil for a township in Jiangsu Province, China. Chemosphere 2017;168:1658-1668.

3. Wei B, Yang L. A review of heavy metal contaminations in urban soils, urban road dusts and agricultural soils from China. Microchem. J. 2010;94:99-107.

4. Wang G, Zhang S, Zhong Q, et al. Effect of soil washing with biodegradable chelators on the toxicity of residual metals and soil biological properties. Sci. Total Environ. 2018;625:1021-1029.

5. Fonseca B, Pazos M, Tavares T, Sanroman MA. Removal of hexavalent chromium of contaminated soil by coupling electrokinetic remediation and permeable reactive biobarriers. Environ. Sci. Pollut. Res. Int. 2012;19:1800-1808.

6. Tang X, Li Q, Wang Z, Hu Y, Hu Y, Li R. In situ electrokinetic isolation of cadmium from paddy soil through pore water drainage: Effects of voltage gradient and soil moisture. Chem. Eng. J. 2018;337:210-219.

7. Mandal BK, Suzuki KT. Arsenic round the world- a review. Talanta 2002;58:201.

8. Showtyk W, Norton S, Farmer J. Summary of the Workshop on Peat Bog Archives of Atmospheric Metal Deposition. Water Air Soil Pollut. 1997;100:213-219.

9. Bolan N, Kunhikrishnan A, Thangarajan R, et al. Remediation of heavy metal(loid)s contaminated soils-to mobilize or to immobilize? J. Hazard. Mater. 2014;266:141-166.

10. Rosestolato D, Bagatin R, Ferro S. Electrokinetic remediation of soils polluted by heavy metals (mercury in particular). Chem. Eng. J. 2015;264:16-23. 
11. Gupta VK, Mohan D, Sharma S, Park KT. Removal of chromium(VI) from electroplating industry wastewater using bagasse fly ash - a sugar industry waste material. Environmentalist 1998;19:129-136.

12. Race M, Ferraro A, Fabbricino M, et al. Ethylenediamine-N,N'Disuccinic Acid (EDDS)-Enhanced Flushing Optimization for Contaminated Agricultural Soil Remediation and Assessment of Prospective $\mathrm{Cu}$ and $\mathrm{Zn}$ Transport. Int. J. Environ. Res. Public Health 2018;15(3):543.

13. Yan X, Liu Q, Wang J, Liao X. A combined process coupling phytoremediation and in situ flushing for removal of arsenic in contaminated soil. J. Environ. Sci. (China) 2017;57:104-109.

14. Xu Y, Xia W, Hou H, Zhang J, Qian G. Remediation of chromium-contaminated soil by electrokinetics and electrokinetics coupled with CaAl-LDH permeable reaction barrier. Environ. Sci. Pollut. Res. Int. 2017;24:20479-20486.

15. Yuan C, Hung CH, Chen KC. Electrokinetic remediation of arsenate spiked soil assisted by CNT-Co barrier-The effect of barrier position and processing fluid. J. Hazard. Mater. 2009;171:563-570.

16. Sillanpaaa JVM, Latostenmaab P. Electrokinetic soil remediation critical overview. Sci. Total Environt. 2002;289:97-121.

17. Nasiri A, Jamshidi-Zanjani A, Khodadadi Darban A. Application of enhanced electrokinetic approach to remediate Cr-contaminated soil: Effect of chelating agents and permeable reactive barrier. Environ. Pollut. 2020;266:115197.

18. Fardin AB, Jamshidi-Zanjani A, Darban AK. Application of enhanced electrokinetic remediation by coupling surfactants for kerosene-contaminated soils: Effect of ionic and nonionic surfactants. J. Environ. Manage 2021;277:111422.

19. Adhami S, Jamshidi-Zanjani A, Darban AK. Phenanthrene removal from the contaminated soil using the electrokinetic-Fenton method and persulfate as an oxidizing agent. Chemosphere 2021;266:128988.

20. Li Z, Yuan S, Wan J, Long H, Tong M. A combination of electrokinetics and $\mathrm{Pd}: \mathrm{Fe} \mathrm{PRB}$ for the remediation of pentachlorophenol-contaminated soil. J. Contam. Hydrol. 2011;124: 99-107.

21. Xu Y, Xu X, Hou H, Zhang J, Zhang D, Qian G. Moisture content-affected electrokinetic remediation of $\mathrm{Cr}(\mathrm{VI})$-contaminated clay by a hydrocalumite barrier. Environ. Sci. Pollut. Res. Int. 2016;23:6517-6523

22. Suzuki T, Kawai K, Moribe M, Niinae M. Recovery of Cr as $\mathrm{Cr}(\mathrm{III})$ from $\mathrm{Cr}(\mathrm{VI})$-contaminated kaolinite clay by electrokinetics coupled with a permeable reactive barrier. J. Hazard. Mater. 2014;278:297-303.

23. Ma JW, Wang FY, Huang ZH, Wang H. Simultaneous removal of 2,4-dichlorophenol and Cd from soils by electrokinetic remediation combined with activated bamboo charcoal. J. Hazard. Mater. 2010;176:715-720.

24. Weng CH, Lin YT, Lin TY, Kao CM. Enhancement of electrokinetic remediation of hyper-Cr(VI) contaminated clay by zero-valent iron. J. Hazard. Mater. 2007;149:292-302.

25. Yuan C, Chiang TS. The mechanisms of arsenic removal from soil by electrokinetic process coupled with iron permeable reaction barrier. Chemosphere 2007;67:1533-1542.

26. Cappai G, Gioannis GD, Muntoni A, Spiga D, Zijlstra JJP.
Combined use of a transformed red mud reactive barrier and electrokinetics for remediation of $\mathrm{Cr}$ :As contaminated soil. Chemosphere 2012;86:400-408.

27. Viamajala S, Peyton BM, Gerlach R, Sivaswamy V, Apel WA, Petersen JN. Permeable reactive biobarriers for in situ Cr(VI) reduction: bench scale tests using Cellulomonas sp. strain ES6. Biotechnol. Bioeng. 2008;101:1150-1162.

28. Ding L, Lv W, Yao K, Li L, Wang M, Liu G. Remediation of Cd(II)-contaminated soil via humin-enhanced electrokinetic technology. Environ. Sci. Pollut. Res. Int. 2017;24:3430-3436.

29. Huang D, Wang G, Shi Z, Li Z, Kang F, Liu F. Removal of hexavalent chromium in natural groundwater using activated carbon and cast iron combined system. J. Clean. Prod. 2017;165:667-676.

30. Qian G, Feng L, Zhou JZ, et al. Solubility product (Ksp)-controlled removal of chromate and phosphate by hydrocalumite. Chem. Eng. J. 2012;181-182:251-258.

31. Li Y, Wang J, Li Z, et al. Ultrasound assisted synthesis of $\mathrm{Ca}-\mathrm{Al}$ hydrotalcite for U (VI) and Cr (VI) adsorption. Chem. Eng. J. 2013;218:295-302.

32. Lu H, Liu S, Zhang H, Qiu Y, Zhao J, Zhu Z. Decontamination of Arsenic in Actual Water Samples by Calcium Containing Layered Double Hydroxides from a Convenient Synthesis Method. Water 2018;10(9);1150.

33. Yuan C, Hung CH, Chen KC. Electrokinetic remediation of arsenate spiked soil assisted by CNT-Co barrier-The effect of barrier position and processing fluid. J. Hazard. Mater. 2009;171:563-570.

34. Birnin-Yauri UA, Glasser FP. Friedel's salt, $\mathrm{Ca}_{2} \mathrm{Al}(\mathrm{OH})_{6}(\mathrm{Cl}, \mathrm{OH})$. $2 \mathrm{H}_{2} \mathrm{O}$ - its solid solutions and their role in chloride binding. Cem. Concr. Res. 1998;28:1713-1723.

35. Hoffmann M, Mikutta C, Kretzschmar R. Bisulfide reaction with natural organic matter enhances arsenite sorption: insights from X-ray absorption spectroscopy. Environ. Sci. Technol. 2012;46: 11788-11797.

36. Zhou J, Su Y, Zhang J, et al. Distribution of $\mathrm{OH}$ bond to metal-oxide in Mg3-xCaxFe-layered double hydroxide $(\mathrm{x}=0-1.5)$ : Its role in adsorption of selenate and chromate. Chem. Eng. J. 2015;262:383-389.

37. Wang S, Mulligan CN. Effect of natural organic matter on arsenic release from soils and sediments into groundwater. Environ. Geochem. Health 2006;28:197-214.

38. Chen Y-E, Mao H-T, Ma J, et al. Biomonitoring chromium III or VI soluble pollution by moss chlorophyll fluorescence. Chemosphere 2018;194:220-228.

39. Li T, Wang Y, Guo S, et al. Effect of polarity-reversal on electrokinetic enhanced bioremediation of Pyrene contaminated soil. Electrochim. Acta 2016;187:567-575.

40. Dai Y, Qian G, Cao Y, et al. Effective removal and fixation of $\mathrm{Cr}(\mathrm{VI})$ from aqueous solution with Friedel's salt. J. Hazard. Mater. 2009;170:1086-1092.

41. Qu J, Zhong L, Li Z, Chen M, Zhang Q, Liu X. Effect of anion addition on the syntheses of $\mathrm{Ca}-\mathrm{Al}$ layered double hydroxide via a two-step mechanochemical process. Appl. Clay Sci. 2016;124-125:267-270.

42. Hu B, Liu WX, Gao WW, Han JL, Liu H, Lucia LA. Pseudo-Janus $\mathrm{Zn} / \mathrm{Al}$-based nanocomposites for $\mathrm{Cr}(\mathrm{VI})$ sorption/remediation 
and evolved photocatalytic functionality. Chem. Eng. J. 2015;277:150-158.

43. Zhang P, Qian GR, Cheng HF, Yang J, Shi HS, Frost RL. Near-infrared and mid-infrared investigations of Na-dodecylbenzenesulfate intercalated into hydrocalumite chloride (CaAl-LDH-Cl).
Spectrochim. Spectrochimica Acta Part A 201179:548-553.

44. Li YJ, Gao BY, Wu T, et al. Hexavalent chromium removal from aqueous solution by adsorption on aluminum magnesium mixed hydroxide. Water Res. 2009;43:3067-3075. 